if respiration has ceased) and treating metabolic acidosis. The latter occurs very rapidly when blood supply to the muscles and other tissues is deficient, and must be combated energetically by intravenous sodium bicarbonate. ${ }^{1} 1213$ Thus some doctors will carry with them a large syringe with ampoules of $8.4 \%$ sodium bicarbonate and a mouth-to-mouth plastic airway, waiting for the once-in-a-lifetime opportunity to save a life. Much emotional feeling may be engendered in the operator and his helpers during these procedures, and the usual difficulty-especially with the inexperienced-is to know when to stop further hopeless attempts.

External compression (or closed chest cardiac massage), despite experimental findings to the contrary, ${ }^{10}$ is now considered to be almost as effective as direct (open chest) cardiac massage, and so it seems unlikely that the latter will now be used in resuscitation except perhaps on the operating table. In hospital, while alternating current is probably as effective as direct-current shock when used on fibrillating ventricles with the chest open, ${ }^{1}$ it is probably more harmful to the myocardium. ${ }^{5}$ With the chest unopened it seems that a shock from a direct-current defibrillator is much more likely to be effective, ${ }^{256}$ and this is the type of machine which should now be in general use. The same machine with a synchronizer is now used for electrical conversion of atrial fibrillation and other dysrhythmias to sinus rhythm..$^{514}$

In hospital the selection of patients for intensive monitoring, perhaps in a special unit such as Dr. G. F. Crockett and Mr. A. Barr describe at p. 1173, is often difficult. At least one unit has devised a method of assessing prognosis (the "coronary prognostic index" $)^{15}$ which is based on the patient's age and previous history, the presence and degree of shock, heart failure, and arrhythmia, and Q-wave changes in the electrocardiogram. A maximum score of 28 is theoretically possible and one of 17 has been found to be associated with a mortality rate of over $50 \%$ within 28 days. In the past doctors and nurses have been told to attempt resuscitation only in those persons whose score is less than $17 .{ }^{6}$ Nevertheless, this sort of assessment is impossible in patients who develop cardiac arrest in the street. Many of these patients have sustained a major coronary occlusion, which has rendered a large area of cardiac muscle ineffective. In these cases immediate external cardiac compression will usually preserve an inefficient but supportive circulation temporarily, though the chances of successful defibrillation are usually slim and those for long-term survival even worse. This should not deter the doctor from attempting resuscitation, though he should realize that his chances of success are limited.

\footnotetext{
'Robinson, J. S., Sloman, G., Mathew, T. H., and Goble, A. J., Amer, Heart $\mathscr{f} ., 1965,69,740$.

${ }^{2}$ Yu, P. N., Fox, S. M., Imboden, C. A., and Killip, T., Mod. Con. cardiovasc. Dis., 1965, 34, 23 .

s Jude, J. R., Dis. Chest, 1963, 43, 34.

- Smirk, F. H., and Palmer, D. G., Amer. F. Cardiol., 1960, 6, 620.

Lown, B., Amarasingham, R., and Newman, J., F. Amer. med. Ass., 1962, $182,548$.

Semple, T., Dall, J. L. C., Lancaster, W. M., Wang, I., Grigor, K., and Pell, A. A. F., Scot. med. F., 1963, 8, 475.

Portal, R. W., Davies, J. G., Robinson, B. F., and Leatham, A. G., Brit.

med.F., 1963, 1, 636 .
Minogue, W. F., Smessart, A. A., and Grace, W. J., Amer. F. Cardiol., 1964, 13, 25 .

- Scherf, D., and Bornemann, C., ibid., 1960, 5, 30

10 MacKenzie, G. J., Taylor, S. H., McDonald, A. H., and Donald, K. W., Lancet, 1964, 1, 1342 .

"Wetherill, J. H., and Nixon, P. G. F., ibid., 1962, 1, 993.

18 Stewart, J. S., Stewart, W. K., Morgan, H. G., and McGowan, S. W., Brit. Heart F., 1965, 27, 490.

${ }^{13}$ Shaw, G., Smith, G., and Thomson, T. J., Resuscitation and Cardiac Pacing, p. 66, 1965. Cassell, London.

14 McDonald, L., Resnekov, L., and O'Brien, K., Brit. med. F., 1964, 1, 1468

15 Peel, A. A. F., Semple, T., Wang, I., Lancaster, W. M., and Dall, J. L. G., Brit. Heart f., 1962, 24, 745.
}

\section{Not so Fast}

In addition to untold suffering and bereavement road: accidents in Great Britain are currently estimated to cost the community more than $£ 200 \mathrm{~m}$. a year. Medical treatment for the casualties alone costs about $£ 13 \mathrm{~m}$. a year. ${ }^{1}$ Anything. which shows promise of reducing this charge on the nation's economy and medical services therefore deserves careful attention. One such measure is the speed limit, which has been a feature of built-up areas in Britain since 1935 and was this year applied to some 400 miles of important rural main roads having an accident record above the national average. What is the evidence for its value ?

The distance required to bring a vehicle to rest, perhaps in order to avoid a collision, is not directly proportional to. the speed but to the square of the speed." For instance, a car travelling at 30 m.p.h. moves through a distance of $44 \mathrm{ft}$. in one second and cannot stop in less than $75 \mathrm{ft}$. under ideal conditions of road, vehicle, and driver. At 60 m.p.h. it travels $88 \mathrm{ft}$. in one second but requires $240 \mathrm{ft}$. to stop in ideal conditions. ${ }^{3}$ Considerably more than these distances is usually needed in practice, but observations on the road have shown that drivers often travel much closer to the vehicle in front than the minimum safe distance. ${ }^{4}$ Of the accidents on the London-Birmingham motorway reported in 1960 and 1961 (apart from those at terminals and junctions) $24 \%$ involved a vehicle colliding with the rear of another moving vehicle and $6 \%$ involved collision with a stationary vehicle. ${ }^{5}$ Faulty brakes are more prevalent than might be thought. For instance, spot checks of vehicles on the road made by. Ministry of Transport examiners in 1963 showed that onequarter had defective brakes. ${ }^{6}$ Furthermore, the effects of a mechanical failure of some part of the vehicle (for example, burst tyres, overheating, or shattered windscreens) are also aggravated by high speed.

When the road surface is wet, as it is for about one-fifth of the time in this country, the risk of a skid is greater at high speeds than at low speeds because the layer of water between the tyre and road surface is not always squeezed away fast enough for adequate contact between the road and tyre to be maintained. Surfaces which are smooth or have relatively few rough projections also offer less resistance to skidding as the speed of a vehicle increases. Other effects of high speed are of special interest to medical men. For instance, a driver's estimate of the speed of a vehicle is less accurate at higher speeds ${ }^{7}$; lettering on road signs which is legible at low speeds becomes inadequate for conveying messages to a fast-travelling driver ${ }^{8}$; and some types of individual, after taking alcohol, drive at more than their normal speeds. ${ }^{9}$

These results of research into road safety indicate that when vehicle speeds increase and other things remain constant there is a deterioration in each of the factors making for safety. Therefore a reasonable inference is that accidents would be fewer if speeds were lower, and many studies made before and after the imposition of speed limits in Great Britain or abroad have verified that. For instance the 30 m.p.h limit imposed in built-up areas of Great Britain in 1935 was followed by a $6 \%$ reduction in accidents causing injury $^{10}$; a similar limit imposed in Northern Ireland in 1956 was followed by a $24 \%$ reduction in such accidents. ${ }^{11}$ A 40 m.p.h. limit applied during the late 1950 s to same main roads in the London area formerly without a speed limit brought a reduction of $20 \%$ in accidents causing injury, ${ }^{12}$ and a similar limit adopted in Jersey in 1959 reduced fatali 
and serious accidents by nearly one-half. ${ }^{10}$ A speed limit on some lengths of autobahn in West Germany reduced accidents by $30 \% .^{10}$ After the imposition of temporary speed limits at week-ends in Sweden it was concluded that accidents were fewer and less severe when they were applied than could have been expected if they had not been. ${ }^{13}$ Conversely, removing the 30 m.p.h. limit from some roads in Great Britain between 1945 and 1953 appears to have led to an increase in accidents causing injury, ${ }^{14}$ and raising the limit from 30 to 40 m.p.h. on some main roads near London in 1958 was followed by an increase in fatal and serious accidents. ${ }^{12}$

In the U.S.A. speed limits have long been an accepted means of promoting safer and orderly movement of traffic. There, nearly all roads, including those corresponding to our motorways, have speed limits ; in towns the limits are frequently as low as 20 m.p.h. and in oper country usually 65 m.p.h., though sometimes 60 or even 50 m.p.h. ${ }^{15}$ On the New York State Thruway, which has a speed limit of 65 m.p.h., the average speed of all vehicles in 1962 was 57.2 m.p.h. ${ }^{16}$; the average speed of vehicles on six British motorways (without a speed limit) in 1964 was 53.5 m.p.h. The average fatality rate on the major turnpike roads of U.S.A. in 1962 was 2.4 per 100 million miles travelled, ${ }^{16}$ while on the London-Birmingham motorway the corresponding rate in 1961-3 was 5.1 per 100 million miles travelled. ${ }^{17}$

More than 3,000 people were killed and over 100,000 injured on roads without a speed limit in Britain during 1964. The figures cited here suggest that the imposition-and enforcement-of speed limits on these roads would reduce the number of accidents and diminish the effects of collisions. They also support the Minister of Transport's evident intention of making more use of speed limits on roads. Permanent limits of 50 m.p.h. are now in operation on some 400 miles of rural main roads, and further lengths are to be restricted later. A 40 m.p.h. limit has been imposed on the elevated portion of M4 near Chiswick, and the question of speed limits for motorways in general is being considered. ${ }^{18}$ As in any other field of activity, no single measure will by itself prevent all accidents, but a limitation on the speed of vehicles appears at present to be an expedient which can bring about an appreciable reduction.

${ }^{1}$ Road Research Laboratory, Research on Road Safety, 1963, p. 479. H.M.S.O., London.

2 ibid., 1963, p. 378. H.M.S.O., London.

3 Ministry of Transport, Highway Code, H.M.S.O., London.

- Harris, A. J., Following Distances and the Probability of Danger of Collision between Vehicles, 1959. Road Research Laboratory, Research Note No. 3384. Unpublished.

${ }^{5}$ Newby, R. F., and Johnson, H. D., Traffic Engineering and Control, 1963, 4, 550.

- Ministry of Transport and Scottish Development Department, Road Accidents, I963, 1964. H.M.S.O., London.

'Moore, R. L.. in International Study Week in Traffic Engineering $I-6$ October, 1956, Stresa, Italy, 1956. World Touring and Automobile Organization, London.

8 Traffic Engineering and Control, 1962, 3, 685.

- Drew, G. C., Colquhoun, W. P., and Long, H. A., Brit. med. F., 1958, 2,993 .

${ }^{10}$ Smeed, R. J., Roads and Road Construction, 1960, 38, 393; 1961, 39, 15.

${ }_{11}$ Garwood, F., and Duff, J. T., Changes in accident frequency after changes in speed limits in the United Kingdom. Fifth International Study Week in Traffic Engineering, 26 September-1 October, 1960, Nice, France. Theme VI., 1960. World Touring and Automobile Organization, London.

13 Newby, R. F., Traffic Engineering and Control, 1963, 3, 678.

${ }^{13}$ Ministry of Communications, Stockholm. The Application of Temporary Road Speed Limits in Sweden, I96I-1962, 1965. Stockholm.

14 Garwood, F., Some Applications of Statistics in Road Safety Research, 1956. Manchester Statistical Society, Manchester.

${ }^{15}$ National Highway Users Conference, Inc., State Motor Vehicle Speed Limits, 1962. National Highway Users Conference, Inc., Washington, D.C.

New York.

${ }^{17}$ Department of Scientific and Industrial Research, Road Research, r963, 1964, p. 44. H.M.S.O., London.

${ }^{18}$ Hansard (Commons), i July 1964.

\section{Physiology of Lactation}

In a pamphlet ${ }^{1}$ published by the World Health Organization a Scientific Study Group summarize the present state of knowledge of the physiology of lactation. They make a well-justified plea for more research. There is no lack of facts on the various aspects of lactation in animals, as is obvious from a recent review of the knowledge in this field. $^{2}$ But even a superficial study of the literature shows that there are wide differences between species and that knowledge of lactation gained from experimental animals cannot be directly applied to man. Our knowledge of human lactation is sparse, and apart from the pioneer clinical studies of Waller and the work of Gunther, Hytten, and the Newtons few have devoted their attention to its problems.

In Great Britain to-day probably only a minority of mothers successfully establish lactation and continue to breastfeed their infants for any appreciable length of time. The reasons for the lack of enthusiasm in both the mothers and their attendants are complex. Social factors undoubtedly play a large part in determining this rejection of a natural function, a choice that is made easier because satisfactory artificial-milk substitutes are readily available. In a privileged community such as ours it is often difficult to find convincing arguments that will persuade the perplexed new mother to continue the struggle that is often required to establish lactation, especially when she is surrounded by others who suffer no discomfort and whose artificially fed infants seem to thrive equally well if not better than her own.

The main argument used in support of breast-feeding at present is that it favours the establishment of a satisfactory relationship between mother and child, one that is of lasting psychological benefit to both. Would it not be possible to produce convincing and tangible evidence in support of this argument ? The reflex release of oxytocin as a result of the suckling stimulus undoubtedly helps the involution of the genital organs. Moreover, the mothers of breast-fed infants seem to have less trouble with irregular bleeding and vaginal discharge in the puerperium, whereas the use of oestrogens for the suppression of lactation is often blamed for irregular bleeding, slow involution, and even later in life for an increased incidence of carcinoma of the breast. Surely we could replace such clinical impressions, some of which are no more than rumours, by acceptable proof ? Breast milk provides the infant with a certain amount of passive immunity. Is there no way of showing with certainty whether or not the human infant derives worth-while benefits when it is fed by its mother ?

In contrast the advantages of breast-feeding are still obvious in an underprivileged community, where the infant mortality rate from enteric diseases remains high. Further, where there is a lack of first-class protein the breast-fed infant is undoubtedly better off, because the protein content of the milk even of undernourished mothers is maintained at a normal level at the expense of the maternal tissues. In developing communities, therefore, there are two main problems associated with human lactation that need an urgent solution. What is the ideal diet for the nursing woman so that she can maintain adequate lactation without depriving herself ? And is it possible to improve the failing lactation of those mothers in whom the ability to breast-feed may make the difference between life and death for the child ?

\footnotetext{
Wld Hlih Org. techn. Rep. Ser., 1965, 305.

Milk: The Mammary Gland and its Secretions, ed. S. K. Kon and A. T. Cowie, 1961. London.
} 